ISSN: 0213-2079 - ISSN electrónico: 2386-3889

DOI: https://doi.org/10.14201/shhmo20204216591

\title{
LA RED DE SALINAS Y EL COMERCIO DE LA SAL EN EL ESTUARIO DEL TINTO DURANTE LA EDAD MODERNA: HUELVA, SAN JUAN DEL PUERTO, PALOS DE LA FRONTERA Y MOGUER $^{1}$
}

\section{The salt pans network and the salt trade in the estuary of the Tinto during the Modern Age: Huelva, San Juan del Puerto, Palos de la Frontera y Moguer}

\section{David GONZÁLEZ CRUZ \\ Universidad de Huelva \\ david@uhu.es}

Fecha de recepción: 03/04/2020

Fecha de aceptación: 08/05/2020

RESUMEN: La sal durante el Antiguo Régimen se constituyó en uno de los instrumentos de desarrollo de la economía de las localidades asentadas en torno al río Tinto (Andalucía occidental, España) a causa de haber sido un producto fundamental para la conservación de los alimentos, la elaboración de los suministros y el aprovisionamiento de las embarcaciones que partieron de sus puertos desde la época de los descubrimientos. Como consecuencia de la demanda de este recurso marino existía una red de salinas destinadas al consumo comarcal y a los circuitos comerciales que conectaban las rutas atlánticas y las mediterráneas. Precisamente, la

1. La realización de esta investigación ha dispuesto de una ayuda económica concedida al Grupo de Investigación «Mentalidad, sociedad y medioambiente en Andalucía e Iberoamérica» (HUM-785) por el Plan Andaluz de Investigación con financiación de la Junta de Andalucía y de los fondos FEDER de la Unión Europea. 
rentabilidad mercantil de la explotación del mencionado producto y el régimen fiscal que lo gravaba motivó que los linajes nobiliarios (Medina Sidonia, Portocarrero, Saltés y Cifuentes) procuraran dominar la titularidad de la explotación de las salinas desde la Baja Edad Media a pesar de haber sido en su origen una prerrogativa regia.

Palabras clave: salinas; comercio; sal; río Tinto; nobleza.

ABSTRACT: Salt during the Old Regime became one of the instruments for the development of the economy of the towns located around the Tinto river (western Andalusia, Spain) because it was a fundamental product for the preservation of food, the preparation of the supplies and logistics for the ships that left their ports since the time of the discoveries. As a consequence of the demand for this marine resource, there was a network of salt flats destined for regional consumption and the commercial circuits that connected the Atlantic and Mediterranean routes. Precisely, the commercial profitability of the exploitation of the aforementioned product and the tax regime that imposed on it, motivated that the noble lineage (Medina Sidonia, Portocarrero, Saltés and Cifuentes) tried to dominate the ownership of the exploitation of the salt pans since the late Middle Ages despite having originally been a royal prerogative.

Keywords: salt pans; commerce; salt; river Tinto; nobility.

\section{FUENTES Y CONSIDERACIONES GENERALES}

Los resultados que ahora presentamos suponen un avance en el conocimiento de las salinas en Andalucía y de la comercialización de la sal en los circuitos internacionales; ciertamente se trata de una temática escasamente estudiada hasta el presente, salvo excepciones como las protagonizadas por el profesor Miguel Ángel Ladero Quesada para el conjunto del reino de Castilla. Con todo, era necesario realizar un estudio específico de la producción de este recurso en el estuario del Tinto y de su explotación por las diferentes casas nobiliarias con jurisdicción en la zona, pues resultó una herramienta básica en el avituallamiento de las embarcaciones que participaron en el descubrimiento de América y en otras empresas atlántico-africanas que se desarrollaron por parte de los marinos onubenses a partir del siglo XV; asimismo fue un producto que favoreció la inserción de los puertos naturales del río Tinto en las rutas mercantiles que unían la Europa atlántica con los países mediterráneos.

Desde luego, este artículo expone los primeros resultados de una investigación que debe prolongarse en próximos años, si bien permite ofrecer una visión 
novedosa de la actividad salinera en este espacio geográfico de Andalucía occidental integrándolo dentro del marco general de la corona de Castilla. Con este objetivo se ha llevado a cabo una metodología consistente en el cruzamiento de diferentes fuentes de origen muy diverso; entre ellas las procedentes del Archivo General de Simancas, Archivo Histórico Nacional, Archivo General de Indias, Real Academia de la Historia (España), Archivo de la Fundación Casa de Medina Sidonia, Archivo Histórico Provincial de Huelva, archivos municipales de Moguer, Huelva y San Juan del Puerto, Archivo Histórico de Protocolos de Guipuzkoa, pleitos colombinos, ordenanzas señoriales y algunas colecciones documentales.

Teniéndose en cuenta esta contextualización inicial, las salinas de los estuarios de los ríos Tinto y Odiel estaban situadas en sus marismas, en donde se construían los estanques que se llenaban mediante el flujo de las mareas para después generar sal como consecuencia de la evaporación de las aguas. Sin duda, en la Edad Moderna era un producto muy valorado en las costas andaluzas por diferentes razones; por un lado, era una sustancia imprescindible para la conservación del pescado que se capturaba y comercializaba, así como de otros alimentos; también era necesaria para formar parte de la dieta de sus habitantes y del ganado. En este contexto, las poblaciones que mantenían una actividad pesquera permanente, como era el caso de las diferentes localidades del litoral onubense, estaban obligadas a producir cloruro de sodio con el fin de destinarlo a las salazones de peces que posteriormente eran introducidos en los mercados locales, nacionales y europeos ${ }^{2}$. De ello fue un ejemplo evidente Martín Alonso Pinzón, codescubridor de América, quien se dedicaba entre sus quehaceres a transportar a otros puertos europeos el pescado salado capturado en las aguas atlánticas; de ahí que Cristóbal Colón, con objeto de reclutar a la tripulación y preparar su primer viaje a América, tuviera que esperar a este marino de Palos, puesto que en 1492 se encontraba llevando a la ciudad de Roma una embarcación cargada de sardinas. De este hecho dejaba constancia en los pleitos colombinos en 1535 el testigo Pedro Alonso Ambrosio, vecino de Palos:

«... sabe e vido e conosçió al dicho Martín Alonso Pinçón que hera onbre sabio en el arte de la mar e navegaçión y era piloto (...) e quel dicho (...) fue a su costa a Roma en su barco cargado de sardina (...), venido el dicho Martín Alonso Pinçón de Roma con el dicho rrecabdo el dicho Almirante Colón se vino a su casa de la villa de Palos e habló con el dicho Martín Alonso e allí se ynformó dél e ystruyó dél de la dicha navegación e le dio avisos nesçesarios para descubrir las dichas Yndias...(Muro, 1964: 242-243)»

2. Como referencia de la influencia que tuvo la pesca en la demanda de consumo de sal puede reseñarse el dato que proporciona un acta capitular de Ayamonte, pues decía que un millar de sardina en fresco necesitaba de «una tercia parte de fanega de sal» (González Cruz, 1995: 142). 
Sin duda, la técnica de la salazón era trascendental en la pesca de altura desarrollada en la costa atlántico-africana, pues era una opción viable para transportar la carga debidamente conservada en la larga distancia que separaba la Península Ibérica de los lejanos caladeros; no en vano, algunos vecinos de Moguer y de Palos se hallaban ocupados en esta tarea en la zona de Guinea ${ }^{3}$ y Cabo Bojador desde el último tercio del siglo XV.

Precisamente, las expediciones exploratorias o bélicas en la costa guineana, en las que participaron activamente los marinos de la Baja Andalucía a fines de la Edad Media y principios de la Edad Moderna, requerían cuantiosas cantidades de sardinas y de carne salada con objeto de surtir de víveres a los miembros de las tripulaciones. En efecto, en la relación de gastos de la armada comandada por Charles de Valera que llevó a cabo el ataque naval a Guinea durante la guerra de sucesión al trono mantenida entre los partidarios de Isabel la católica y Alfonso V de Portugal consta, al menos, que se llevaron para su manutención 2.000 sardinas arencadas, otras especies de pescado no especificadas en la documentación y carne de vaca, junto a alimentos como bizcochos, garbanzos, vino, galletas, ajos, y vinagre, entre otros (Aznar, 2002: 408, 416-423). En concreto, en la mencionada empresa marítima tuvieron una evidente relevancia algunos vecinos de Moguer que capitanearon diferentes carabelas; son los casos de Juan Quintero, Juan de Boria, Juan de Coto y Rodrigo Quintero.

Desde luego, esta experiencia gastronómica obtenida en las navegaciones atlántico-africanas y mediterráneas sería trasladada posteriormente a la preparación de las armadas descubridoras de las tierras de las Indias, puesto que los alimentos salados formaron parte de la dieta habitual de los marinos enrolados. A modo de muestra, en el tercer viaje de Colón las carabelas «Niña» $\mathrm{y}$ «Santa Cruz», en las que navegaron diferentes vecinos de Moguer y Palos ${ }^{4}$, contaban en 1498 para la manutención de todos los integrantes de la tripulación con 15 serones de cerdo salado, un cuarto de tonel y un barril de sardinas, tres quintales y dos serones de tocino, entre otros suministros (Pérez, 1994: 1033-1042). De igual modo, la armada organizada por el gobernador Pedrarias Dávila en 1513 con objeto de viajar a Castilla del Oro

3. De ello es expresivo, entre otros documentos, una real cédula y una carta requisitoria relativa al robo sufrido por dos moguereños, que fue dirigida por Carlos I al rey de Francia el 22 de noviembre de 1527: «El Rey (...) por Martín Beltrán e Juan Beltrán, vezinos de la villa de Moguer me hizieron relaçión que de mes e medio a esta parte llevando un nabío cargado de armazón a la pesquera de la Guinea, de valor de más de ochoçientos ducados para traer pescado para el probeymiento de la cibdad de Sevilla çiertos françeses gelo abían tomado e robado e dexado a ellos e sus compañeros desnudos...» Archivo Histórico de Protocolos de Guipuzkoa (AHPG) GPAH 3/0297, A:10r-11r

4. Juan Bermúdez y Pedro Francés, ambos vecinos de Palos, fueron los maestres de las carabelas Santa Cruz y Santa Clara (o Niña), respectivamente (Fernández Navarrete, 1829: 510). 
DAVID GONZÁLEZ CRUZ

LA RED DE SALINAS Y EL COMERCIO DE LA SAL EN EL ESTUARIO DEL TINTO DURANTE

LA EDAD MODERNA: HUELVA, SAN JUAN DEL PUERTO, PALOS DE LA FRONTERA Y MOGUER

cargó, entre otros víveres, 440 millares de sardinas blancas de Huelva envasadas en pipas con sal con el fin de que no se corrompieran durante la travesía atlántica (Mena, 1988: 406).

\section{LA GEOGRAFÍA SALINERA}

Ciertamente la necesidad de disponer de sal en los municipios del estuario del Tinto originó que en todos ellos se instalaran una o varias salinas desde principios de la Edad Moderna originando una circuito lucrativo de este producto; no obstante, su evolución no fue homogénea, puesto que mientras que en Huelva y San Juan del Puerto funcionaron durante el siglo XVIII manteniéndose la actividad en época contemporánea, en Moguer y Palos dejaron de producir en el Setecientos como consecuencia del declive de las pesquerías y del descenso del tráfico comercial en ambas localidades. En concreto, en Moguer se atestigua la presencia de una salina en el entorno del lugar de Val de María ${ }^{5}$, en el límite con el término municipal de Palos, según se advierte en un pergamino redactado en 1481; si bien existen igualmente referencias de otra de posterior creación situada en la dehesa de Mampoy sobre la que se generó un conflicto jurisdiccional al que se hará referencia en otro apartado de este estudio.

Por su parte, en Palos se observa la explotación de la sal en sus marismas, al menos desde antes del descubrimiento de América; no en vano, la mitad de la villa comprada por la Corona al linaje de los condes de Cifuentes tenía entre sus ingresos el rendimiento de unas salinas, cuya administración se la encargaron los reyes católicos al genovés Francisco Pinelo -jurado y fiel ejecutor de Sevilla y primer factor de la Casa de Contratación- mediante un poder otorgado el 20 de junio de 1492 con la finalidad de que las arrendara por el procedimiento de almoneda durante seis años junto a los molinos, tierras, pechos, tributos, heredamientos, derechos, censos e «cualesquier cosas pertenecientes a la dicha mitad de Palos» ${ }^{6}$. Más tarde, en 1494, comprobamos que los duques de Medina Sidonia tenían entre sus rentas la sal producida en la villa de Palos (Ladero, 2015); con todo, a mediados del siglo XVIII la elaboración de este producto despareció de las marismas de la localidad, ya que las respuestas generales del Catastro de Ensenada afirman que las salinas que había en el término municipal no producían nada «porque no existen» ${ }^{7}$.

5. Escritura sobre delimitación de los términos de los concejos de Moguer y Palos. Archivo Municipal de Moguer (AMM), pergamino no 25 del Libro de Privilegios, 13 de octubre de 1481 (González Gómez, 1977: 266).

6. Archivo General de Simancas (AGS), Registro General del Sello (RGS), leg. 149206, no 135. (González Cruz, 2016: 115-116).

7. AGS, Catastro de Ensenada, Respuestas Generales, leg. 562, fol. 1254. 


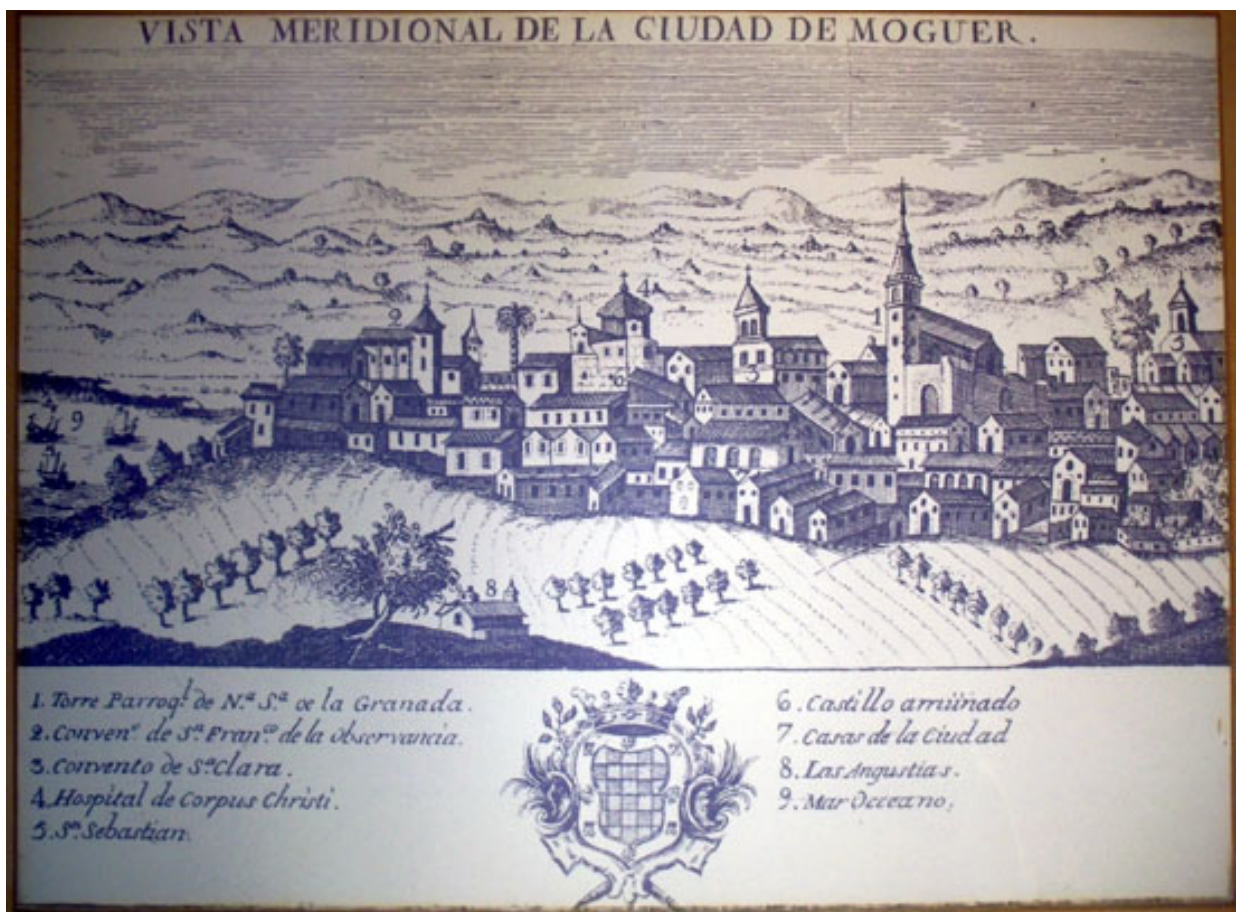

Imagen 1. Vista de la ciudad de Moguer en el siglo XVIII. En la parte izquierda de la imagen se aprecia el puerto con embarcaciones y las marismas donde estaban las salinas (Espinalt, 1795: 184)

Por otro lado, en San Juan del Puerto la actividad salinera queda atestiguada documentalmente de forma inmediata a la fundación de la localidad y, en este sentido, se ha podido constatar en los fondos archivísticos, que la explotación de la sal en su término municipal es coetánea a la época de los descubrimientos de las tierras americanas. El propio padrón de cuantías de 1503 reseña a dos individuos avecindados en la villa que ejercían el oficio de salinero ${ }^{8}$. Unos años más tarde, a partir de 1509-1510, se aprecian en los libros de cuentas del condado de Niebla existentes en el archivo de la Fundación Casa Medina Sidonia ${ }^{9}$ y en el fondo Osuna del Archivo Histórico Nacional las rentas generadas por las salinas ${ }^{10}$. Posteriormente, en la década de los sesenta del siglo XVI, en un expediente existente en el Archivo General de Indias, se

8. Archivo de la Fundación Casa Medina Sidonia (AFCM), leg. 959, Padrón de cuantías de San Juan del Puerto.

9. AFCM, leg. 2429.

10. Archivo Histórico Nacional (AHN), Sección Nobleza, Osuna, C110, D. 1-11. 
detecta la comercialización de la sal mediante embarcaciones holandesas que acudían al puerto de San Juan. Asimismo, según los datos extraídos del Archivo Municipal de San Juan del Puerto, del Archivo Histórico Nacional y de los protocolos notariales depositados en el Archivo Histórico Provincial de Huelva ${ }^{11}$ se ha podido localizar el emplazamiento de las salinas en las marismas situadas junto a la calle Toledillo (también denominada del Toledo), en el entorno del huerto del convento de los frailes carmelitas ${ }^{12}$ y de la ermita de Nuestra Señora de los Remedios ${ }^{13}$, junto a la denominada Casa de la Sal situada en sus inmediaciones y junto a los esteros del molino de «Caena». Ciertamente, así se desprende de diferentes descripciones como la registrada en el libro de fincas seculares del Catastro de Ensenada ${ }^{14}$ :

«Dn. Gerónimo de Contreras, labrador. Posee una pieza de una fanega de tierra de sembradura de secano de primera calidad, a el sittio de la marisma, distante de la población veintte pasos. Confronta a levante con huerto del combento del Carmen, a poniente con la calle del Toledo, a Nortte con la casa de la Sal, y al Sur con las salinas...»

La continuidad de la actividad salinera en estas marismas fue una realidad durante todo el Antiguo Régimen e, incluso, la potestad señorial sobre ellas pervivió hasta bien avanzado el siglo XIX. En un informe redactado en 1862, que contiene transcripciones documentales de los siglos anteriores, se le adjudicaba su propiedad al conde de Saltés, junto con la Casa de la Sal ${ }^{15}$. Posteriormente, en el siglo XX, la tradición de elaborar sal se conservó mediante la explotación de la actual salina por la empresa «Los Astures», aunque localizada en otro lugar del término municipal situado entre los esteros Bergillos y Juan de Coto (actualmente denominado arroyo Los Prados), junto a la finca arrendada por la cuñada de Cristóbal Colón (González Cruz, 2017: 415-438) y al muelle-embarcadero de minerales construido por The Buitrón and Huelva Railway and Mineral Company Limited.

11. Precisamente, una venta de una casa efectuada por Juan Beltrán Pinzón y adquirida por Manuel de Cantos en 1764 confirma la ubicación de las salinas en la marisma situada junto a la calle del Toledo. Archivo Histórico Provincial de Huelva (AHPH), protocolos notariales de San Juan del Puerto, legajo 5185, fol. 130.

12. Así se deduce también de una descripción de otra finca registrada en el libro de fincas seculares del Catastro de Ensenada: «... pieza de tierra de media fanega de sembradura de secano de segunda calidad; a el sitio de Casa de la Sal: confronta (...) al Norte con Huerto del combento del Carmen y al Sur con la misma huerta de Gerónimo de Contreras...» Archivo Municipal de San Juan del Puerto (AMSJ), leg. 493, fols. 679v-680r.

13. De este modo se reseña en otra descripción del mencionado libro de fincas seculares del Catastro de Ensenada: «Isavel Ramírez, viuda. Posee y vive una casa en la calle de Toledo compuesta de dos cuerpos de vivienda vaxa (...) confronta con casa de la hermita de Nra. Sa. de los Remedios y con la Casa de Sal...» AMSJ, leg. 493, fol. 269.

14. AMSJ, Catastro de Ensenada, leg. 493, fols. 227v-228r.

15. AHN, Sección Nobleza, Baena, C. 253, D. 302-304. 
LA RED DE SALINAS Y EL COMERCIO DE LA SAL EN EL ESTUARIO DEL TINTO DURANTE LA EDAD MODERNA: HUELVA, SAN JUAN DEL PUERTO, PALOS DE LA FRONTERA Y MOGUER

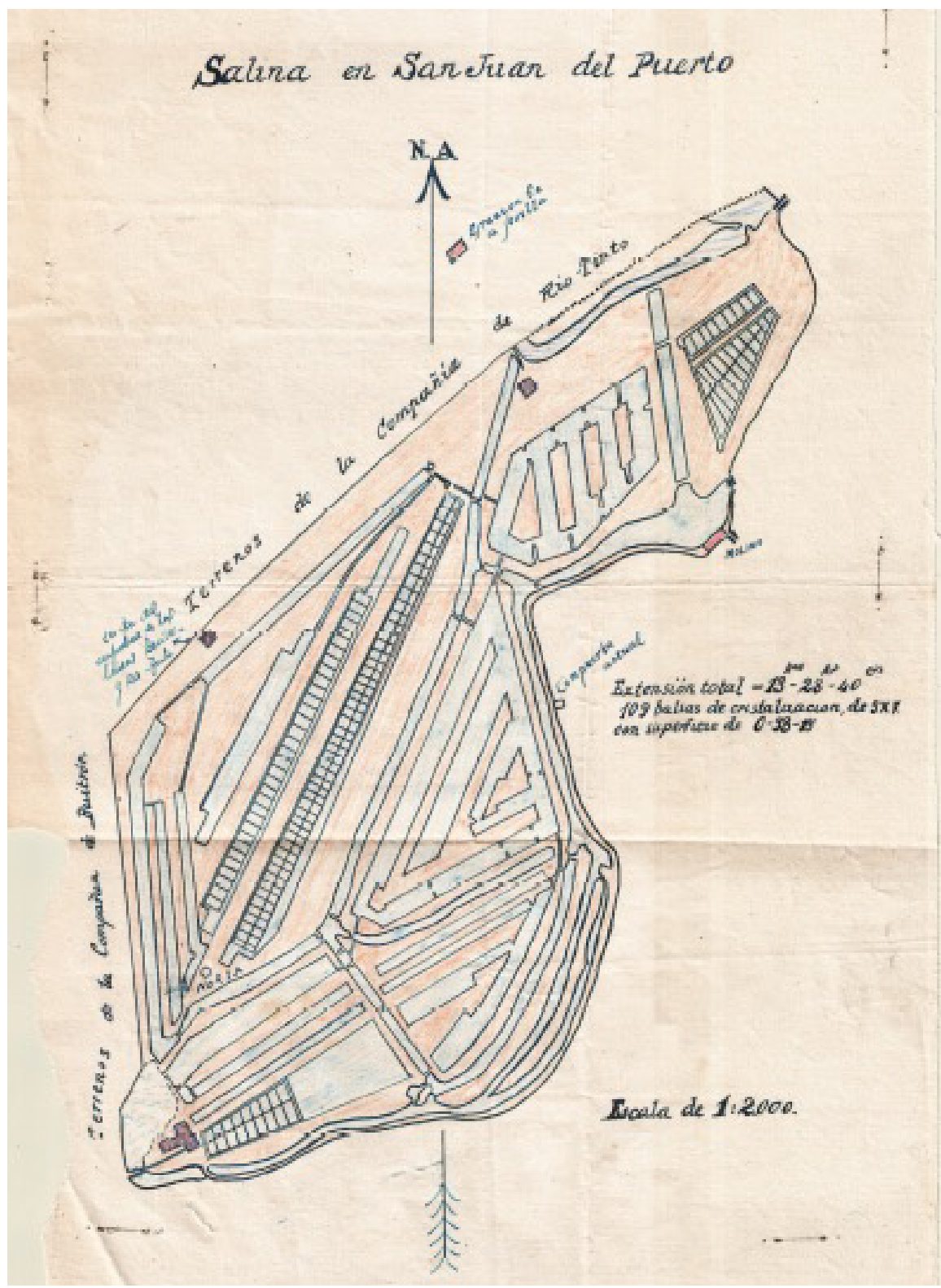

Plano 1. Salina «Los Astures» en 1946, en el que se reseñan las balsas de cristalización. AHPH, Fondo documental de la Delegación del Ministerio de Industria, signatura 14015/009 
En lo que respecta a la villa de Huelva se observa desde comienzos de la Edad Moderna una intensa actividad superando con creces la producción de sal obtenida en cualquiera de los otros tres municipios asentados a orillas del río Tinto. Los primeros datos fiscales cuantificados se remontan al período 1493-96 llegando a alcanzar la Casa Ducal de Medina Sidonia, en época colombina, unas rentas anuales de 170.000 maravedíes por este concepto (Ladero, 2015: 586). Esta elevada cantidad se explica como resultado de que una parte importante de la población se ocupaba de labores marítimas, al tiempo que desde la localidad se desarrollaba un activo comercio de pescado y carnes procedentes de la Sierra y el Andévalo que requerían cloruro de sodio para la conservación de los alimentos que se cargaban en su puerto, ya fuera para aportar víveres a la flota de Indias o, en su caso, para destinarlos al mercado nacional o internacional. En este sentido, la dedicación a las pesquerías formó parte de la identidad socio-profesional de la mayoría de los onubenses. De manera que todavía en el siglo XVIII pervivía esta cultura marinera, tal como lo relataba el ilustrado Juan Agustín de Mora en 1762:

«Oy todavía se trafica en Huelva con barcos viageros, sin contar las jabegas, cazonales, lavadas, chinchorros, y otras muchas embarcaciones, que se emplean en la pesca, ocupan gran parte del pueblo, y surten de pescado la villa, y todo el Reynado de Sevilla» (Mora, 1762:142-143).

En cualquier caso, la demanda de sal había motivado que en la villa de Huelva se prodigara su explotación en numerosas salinas (se han contabilizado 26 a mediados del siglo XVI), las cuales eran mencionadas en una declaración judicial realizada el 30 de julio de 1564 con las siguientes denominaciones ${ }^{16}$ : salina de la Calzada, de la Hamorilla, Grande de la Vega, las dos salinas del Melonar, Darajana, del Coto, de la Casa, del Almendro, de la India, del Congrio, Minas, Alí, Compañera de Alí, Sebastiana, Almudéjar, Esculeña, Grande de Cardeña, Cumplida de Cardeña, Sesenta Lazos y Corriradilla, entre otras. Seguramente la abundancia de espacios dedicados a la elaboración de este producto en la localidad onubense contribuyó a que fuera designada como cabeza de partido de la administración de la renta de salinas de forma que a mediados del siglo XVIII, según las respuestas generales del Catastro de Ensenada ${ }^{17}$, contaba con un administrador y cuatro "dependientes» dedicados a esa labor. A esta jurisdicción fiscal sobre 32 poblaciones del reino de Sevilla (incluidos los municipios costeros y del estuario del Tinto que elaboraban sal) se sumaba su condición de aduana y sede de la gestión de impuestos y de otras rentas; ciertamente sobre ello dejaba constancia el clérigo Juan Agustín de Mora:

16. AHN, Sección Nobleza, Baena, C. 253, D. 302-304.

17. AGS, Catastro de Ensenada, Respuestas Generales, leg. 562, fol. 322. 
«...averla hecho Cabeza de partido en las especies de Aduana, Tabacos, Sal, Jabón, Pólvora, Naypes, y Tercias Reales: de los quales Ramos ay en Huelva Administraciones, y Thesorerías. Acuden a Huelva à proveerse de estas especies la Ciudad de Moguer, Almonte, Gibraleón, San Juan del Puerto, Trigueros, Beas, Niebla, Villaraza, la Palma, Bollullos del Condado, Rosiana, Bonares, Lucena del Puerto, Palos de la Frontera, Aljaraque, Ayamonte, Lepe, Cartaya, la Puebla de Guzmán, los Castillejos, Alosno, Villablanca, Redondela, Sanlúcar de Guadiana, San Silvestre, el Granado, el Almendro, San Bartholomè, Paymogo, Santa Bárbara, Cabezas Rubias, y las Cruces. Estos 32 pueblos del Partido de Huelva deben acudir à ella à surtirse de estas especies» (Mora, 1762: 143).

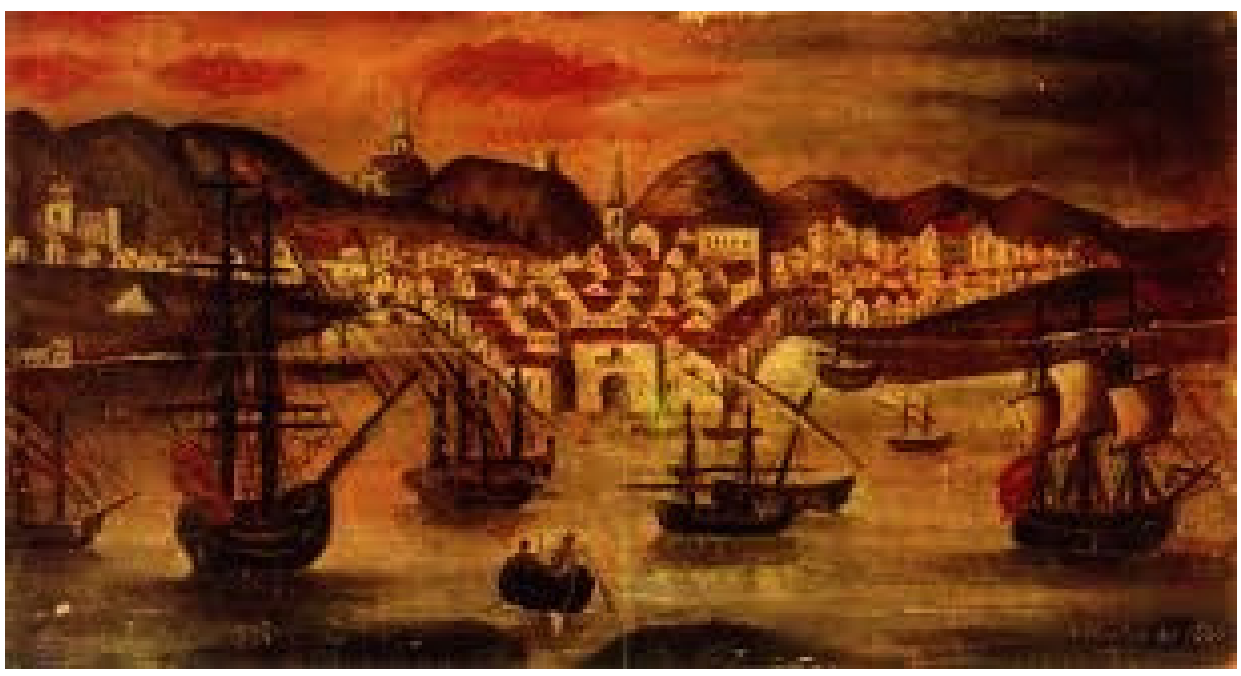

Imagen 2. Óleo sobre tabla que recrea la Huelva del siglo XVIII. A la izquierda de la imagen se observa un montículo de sal situado entre el convento de la Merced y el molino mareal de La Vega. Archivo Municipal de Huelva (AMH), Fondo Díaz Hierro

Con todo, en el siglo XVIII las fuentes documentales apuntan a un descenso de la producción salinera, ya que solamente aluden a la existencia de tres de ellas en funcionamiento ${ }^{18}$ (circunscritas exclusivamente al estuario del río Odiel) frente a las 26 que estaban activas dos siglos antes. La explotación de las tres citadas generaban

18. De este modo lo reseñaba un contemporáneo y vecino de la villa: «Ay en Huelva tres Salinas dentro de Poblado, y orilla del Río dos, una grande, y otra chica. Otra la de Cardeña, que está à quarto de legua al Norte del Poblado» (Mora, 1762: 144). 
entre $12.000^{19}$ y 14.000 fanegas de sal anuales (Mora, 1762: 144). Esta realidad era descrita, entre otros testimonios, por el presbítero José Amador Moreno en torno a 1788 en su respuesta al interrogatorio del geógrafo Tomás López:

«... digo que se benefician sobre el Odiel, en la proximidad de esta villa tres salinas pertenecientes al Excmo. Señor Marqués de Astorga, conde de Altamira. Producen copia de sal, más o menos según la duración de los veranos. Alguna vez han cogido hasta catorce mil fanegas» (Ruíz, 1999: 183).

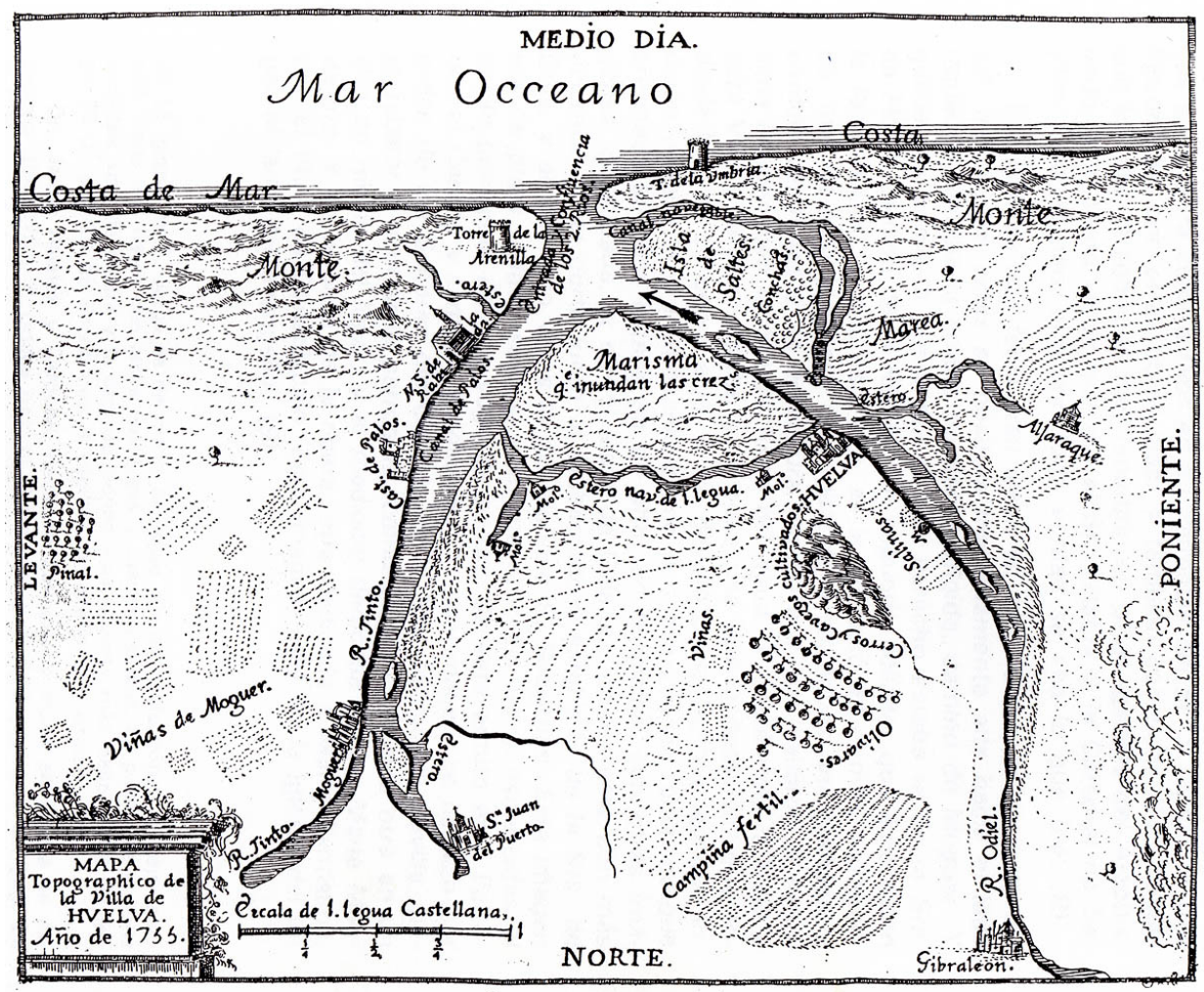

Mapa 1. Topografía de los estuarios del Tinto y del Odiel a mediados del siglo XVIII, en la que José Antonio de Armona y Murga -su autor- dibuja la situación de las salinas de la villa de Huelva a orillas del Odiel (Barco y Gasca, 1755).

19. Este dato de mediados del siglo XVIII en relación con las tres salinas activas nos lo proporciona otro clérigo ilustrado (Barco, 1755: 55). 
En cualquier caso, se debe tener en cuenta en el análisis de la evolución de la explotación salinera que a principios de noviembre de 1755 tuvo lugar el terremoto de Lisboa provocando un gran tsunami sobre el litoral onubense que originó notables perjuicios a las salinas existentes en las marismas y a los almacenes de sal ${ }^{20}$; en concreto, José Antonio de Armona y Murga, nombrado en 1750 por el marqués de la Ensenada contador principal de las aduanas de almojarifazgos y puertos secos del partido de Huelva, decía haber calculado los daños debidos al mencionado movimiento sísmico, así como «el crecido valor de las pérdidas y el de los almacenes de sal que ya estaban prevenidos en la costa para surtir las grandes pesquerías de sardina» (Armona, 2012: 122). Una situación semejante se dio con el cloruro de sodio dedicado a las actividades mercantiles en la costa del marquesado de Ayamonte, pues este producto despareció ante la crecida del mar arruinando así la labor de comercialización del pescado salado que llevaban a cabo las compañías originarias del Levante español asentadas en la zona, tal como puede comprobarse en uno de los impresos que relataban los hechos acontecidos ${ }^{21}$ :

«Se observó por diferentes partes abrirse la tierra en grietas, y por ellas (especialmente en las Marismas) salir crecidas porciones de agua. En las playas immediatas adjacentes, es mucho mayor el perjuicio; pues las Barracas, que se hallaban en ellas se las tragó el mar, consumiendo todos los Caudales, Efectos, Cargamentos, Sales y Dinero, con que se hacían el crecido Comercio, que es notorio. Las compañías Catalanas, Valencianas y Naturales, a cuyo fin tenían en ello establecido numeroso Real, que siempre ha sido costumbre, y es notorio, los destruyó de tal modo, que han quedado los sitios enteramente despoblados y limpios, como si en ellos no huviera havido tal establecimiento, todos innundados, sumergida, y hecha Mar la expresada Playa, sin señal de que lo huviesse sido antes, pereciendo muchas personas...»

Por último, la tradición de la explotación de la sal en las marismas de Huelva ha continuado durante los siglos XIX y XX enlazando con su uso en la industria química onubense a partir de la década de los sesenta de la pasada centuria, cuyos testimonios más actuales son la empresa Salinas del Odiel, que conjuga el uso alimenticio de este producto con otros utilidades propias de la época presente, y las

20. Así describía un relato de suceso el maremoto que sacudió la villa de Huelva en 1755: «Consternado el Vecindario, a vista de esta desgracia se retirò a los Cerros y Colinas más eminentes, no solo con el temor de que se repitiesse este Azote, sino también para libertarse de los movimientos extraordinarios del Mar, que una hora después del Terremoto se conmovió furiosamente, y empujó las Aguas sobre la Costa, de forma, que se creyó que huviesse anegado todo el Pueblo». Relación del terremoto acaecido en Huelva, y lugares circunvecinos el día primero de este mes (1755). Cádiz: Imprenta Real de la Marina.

21. Relación verídica del terremoto y agitación del mar acaecido en la ciudad de Ayamonte el día primero de noviembre de este año de 1755. Sevilla: Imp. Joseph Padrino, p. 6. 
salinas industriales Aragonesas destinadas a proporcionar materia prima a empresas del Polo Industrial de Huelva para la producción de cloro y sosa caustica.

Finalmente, los enclaves salineros existentes entre la orilla occidental del rio Guadalquivir y el río Guadiana se completaban con las salinas de Gibraleón situadas en las marismas del río Odiel a su paso por la mencionada villa (documentadas desde los siglos $\mathrm{XIV}^{22}$ al XVI ${ }^{23}$ ), así como con las existentes en los términos municipales de Ayamonte y Almonte. En ambas localidades estuvieron activas durante toda la Edad Moderna; en concreto, en Ayamonte se tiene constancia que se pretendía construir unas nuevas salinas con el fin de aumentar la producción en el último cuarto del siglo XVIII ${ }^{24}$; por su parte, en las marismas de Almonte existieron cuatro salinas de "seglares» en el Setecientos en el Coto de Doñana ${ }^{25}$ que generaban una utilidad de 120.000 reales según las respuestas generales del Catastro de Ensenada ${ }^{26}$.

\section{TITULARIDAD Y EXPLOTACIÓN DE LAS SALINAS}

Tras la primera organización de la regulación legal de las salinas en las cortes de Nájera en 1137 durante el reinado de Alfonso VII, se reservó su propiedad y rentas a la Monarquía, salvo en los privilegios concedidos y en los que se otorgarían más adelante (Ladero, 1993: 90-91); posteriormente, las Siete Partidas de Alfonso $\mathrm{X}$ confirmaban que las rentas de la sal correspondían a los reyes ${ }^{27}$ y, más tarde, el ordenamiento de Alcalá promulgado en la cortes castellanas celebradas en esta ciudad en 1348, durante el reinado de Alfonso XI, lo explicitaba de una forma clara diciendo que «todas las aguas y pozos salados que son para hacer sal, que todas sus rentas recudan al rey, salvo los que el rey dio por privilegio o cedió por cierto tiempo» ${ }^{28}$.

22. Requerimiento de Alvar Pérez de Guzmán para que se le pagasen las rentas de la villa de Gibraleón, 23 de marzo de 1381 (Pardo, 1980: 151-152).

23. Ejecutoria a favor de la villa de Gibraleón porque los vecinos de Huelva habían destruido unas salinas (AGS, RGS, leg. 150103, 98). Escritura de arrendamiento otorgada por Francisco de Sotomayor - marqués de Gibraleón- a favor de Pedro Álvaro y de su esposa Elvira Núñez para labrar en las marismas de Gibraleón y poder hacer sal. AHN, Sección Nobleza, Osuna, C. 381, D. 48.

24. AGS, Catastro de Ensenada, Respuestas Generales, leg. 560, fols. 315v-316r. Puede verse también el plano correspondiente al proyecto propuesto en 1778 para Ayamonte. AGS, MPD, 67, 014.

25. Las salinas del Coto de Doña Ana están situadas en el entorno de la desembocadura del río Guadalquivir. Puede verse el mapa existente en el Archivo de la Fundación Casa Medina Sidonia (AFCMS), leg. 4166. Año 1760. Consultado el 17 de marzo de 2020. http://www.agfems. com/agfcms_iaph/1760-dehesa-carrizal-figuera/001_img.html

26. AGS, Catastro de Ensenada, Respuestas Generales, leg. 560, fol. 708r.

27. Las Siete Partidas, ley XI.

28. Ordenamiento de Alcalá, caps. 12 y 121. 
No obstante, la posibilidad legal que tenía la Corona para otorgar privilegios en esta materia permitió que Alfonso XI concediera en 1321 a la ciudad de Sevilla y su tierra el monopolio de la venta de sal con sus correspondientes condiciones, cuyo arrendamiento se había hecho merced al concejo de Sevilla por el importe de 36.000 maravedíes anuales, el cual se renovó en $1339^{29}$ (García Fernández, 1988: 72; Ladero, 1993: 93).

Con estos antecedentes la explotación de las salinas andaluzas a comienzos de la Edad Moderna estaba vinculada a los nobles ${ }^{30}$, ciudades y particulares de manera que, como ha estudiado el profesor Ladero, se vendía a un precio libre, mientras que la Monarquía solamente se quedó con el cobro de la alcabala por la venta de la sal (Ladero, 1987: 831); de ahí que en la villa de Huelva todavía en la década de los sesenta del siglo XVIII proporcionaran a la Real Hacienda 170.000 reales por quinquenio (Mora, 1762: 144). Más concretamente en los estuarios de los ríos Tinto y Odiel fue un producto controlado, en líneas generales, por las casas señoriales entre los siglos XV al XVIII: los Portocarrero lo hicieron en el señorío de Moguer y el linaje de los duques de Medina Sidonia en Huelva y San Juan del Puerto. Exclusivamente se observa el caso excepcional de la villa de Palos, pues tras la adquisición por parte de la reina Isabel I de la mitad de la localidad con el fin de que Cristóbal Colón partiera de un puerto real con la intención de descubrir las Indias, los arrendamientos de las salinas situadas en su término municipal pasaron a la titularidad de la Corona; en efecto, mediante la carta de venta ordenada por Juan de Silva-conde de Cifuentes-y sus hermanos a los Reyes Católicos, rubricada en Guadalupe el 24 de junio de 1492, obtenían las salinas y las rentas de Palos poseídas por este linaje $\mathrm{e}^{31}$ (Izquierdo, 1988: 185). Como confirmación de la condición de propiedad real, en el mismo mes de junio de 1492, durante la estancia de los monarcas en Guadalupe, otorgaron un poder a Francisco Pinelo -entonces jurado y fiel ejecutor de Sevillacon el objetivo de que arrendara por el procedimiento de almoneda durante seis años las salinas, junto a las tierras, molinos, tributos, pechos, censos, derechos, heredamientos e «cualesquier cosas pertenecientes a la dicha mitad de Palos»32 (González Cruz, 2016: 115-116). De la anterior jurisdicción señorial sobre la sal

29. Archivo Municipal de Sevilla (AMS), Secc. I, carp. 14. Libro I de Ordenamientos, fols. $54 \mathrm{v}-57 \mathrm{v}$. Secc. $16, \mathrm{n}^{\circ} 18$, fols. $82 \mathrm{r}-84 \mathrm{r}$.

30. De este monopolio señorial por el procedimiento de estanco de la sal se dispone de numerosos ejemplos en Andalucía; entre ellos, junto al privilegio disfrutado por la Casa Ducal de Medina Sidonia, encontramos a los duques de Arcos, que percibían las rentas de las salinas de Tarifa, Puente de León, isla del Vino y Rota. De igual modo, el duque de Medinaceli poseía la jurisdicción de las salinas del El Puerto de Santa María, lo que le reportaba en 1512 cerca de un 10\% del total de las rentas de este señorío -400.000 maravedís- (Iglesias Rodríguez, 2003: 96).

31. AGS, Patronato Real, leg. 35, fol. 5.

32. AGS, Registro General del Sello, leg. 149206, nº 135. 
ofrecía detalles la ordenanza de 27 de enero de 1488, otorgada por Pedro de Silva, en la que se dejaba expresa constancia de que el monopolio de este producto y el arrendamiento de las salinas de Palos eran potestad de la casa condal de Cifuentes de forma que los pescadores y arrendadores no podían utilizar ni introducir en la villa la sal que procediera de otros lugares:

«Por quanto a mi don Pedro de Silva señor de la villa de Palos me fue quejado de parte de los pescadores de esta villa que los arrendadores de la sal de fuera parte el año pasado de ochenta e siete años, habiendo alguna sal por vender de los dichos señores, que porque en el tiempo algunos de los pescadores la tomaren de fuera parte fueren penados por los dichos arrendadores, de que los dichos pescadores reciben agravio por la sal que así metieron contra las condiciones con que los señores les tienen arrendada su renta, mando que en pena de esto ningund arrendador de salinas de esta villa de ende aquel tiempo que la dicha sal metieron fasta el día que este mi mandamiento fue fecho e pregonado, non puedan llevar ni demandar pena ninguna de quantas ayan caído ninguna carabela ni barco sardinero nin otro ningund navío de pesquería.

Así mismo, por quanto los arrendadores de las dichas salina se me quejan que los navíos de esta villa contra los mandamientos de los señores muchas veces toman sal fuera de ella así con poco temor de los señores como por la pena ser poca, de que ellos e las rentas de los dichos señores reciben mucho agravio, mando que de hoy en adelante ninguna carabela ni navío que vaya a pescadas pueda tomar sal fuera de la dicha villa, segund en la forma que los otros señores lo tienen mandado, habiendo en ella sal de los dichos señores, so pena de cinco mil maravedíes, que es la pena que los tiempos pasados antes de este arrendamiento los dichos navíos tenían, la qual pena sea para los arrendadores de las dichas salinas segund en su arrendamiento se contiene (...)

Así mismo mando que desde oy en adelante ningund arrendador de las salinas pueda meter sal en esta dicha villa fasta ser vendida toda la de los señores, so pena de una dobla de oro por cada cahiz que así metiere, la qual pena sea para qualquier de los señores que la quisiere demandar ${ }^{33}$.

Si bien hubo un periodo en el que la propiedad de las salinas de Palos revirtió a la Monarquía por el procedimiento de compra a los Cifuentes, posteriormente consta que pasaron de nuevo a estar en poder de la nobleza; en concreto, en 1494 figura en las rentas de la Casa de Medina Sidonia, al menos, una parte de la sal de las salinas (Ladero, 2015: 590). De igual modo, en las respuestas generales del Catastro de Ensenada de mediados del siglo XVIII se reseña que las salinas que habían existido en la villa de Palos eran propiedad de los duques de Medina Sidonia ${ }^{34}$.

33. Transcripción de las ordenanzas de Palos (Ladero Quesada, 1978: 496-497).

34. AGS, Catastro de Ensenada, Respuestas Generales, leg. 562, fol. 1254. 
En lo que respecta a las salinas de Huelva y San Juan del Puerto las diversas fuentes consultadas indican que desde comienzos de la Edad Moderna estaban bajo la tutela de la casa ducal como monopolio señorial; no en vano, en los libros de cuentas del condado de Niebla aparecen las rentas de la sal obtenidas por los titulares de este linaje en 1510 y en años posteriores ${ }^{35}$. No obstante, los Medina Sidonia mantuvieron una disputa de carácter fiscal con la Monarquía a partir de 1564, cuando Felipe II declaró un estanco de la sal en toda la Corona de Castilla en un contexto de crisis financiera y suspensiones de pago ${ }^{36}$, iniciándose así un contencioso de larga duración entre los Guzmanes y la Real Hacienda (Salas, 2008: 194-195); precisamente, Andalucía quedó exceptuada como consecuencia de la resistencia y oposición mostrada por parte de los grandes linajes nobiliarios de la región respecto a esta decisión regia. Con todo, a partir de ese año comenzó un proceso de negociación y un contencioso judicial entre la Real Hacienda y los duques de Medina Sidonia, si bien es verdad que se adoptó una solución inicial consistente en que los señores podían continuar con la explotación de las salinas a cambio de un impuesto de dos reales por cada arroba de sal producida. Precisamente, de la documentación manejada se desprende que tuvo lugar este acuerdo entre la Casa Ducal y la Corona que permitió a esta estirpe nobiliaria seguir con el monopolio de la actividad salinera en Huelva y San Juan del Puerto; de esta realidad daba cuenta la declaración judicial redactada el 30 de julio de 1564:

«... las salinas de Huelva que la renta e aprovechamiento de ellas perteneciente al Duque mi señor que es medio ducado por cada un cahiz de la sal que de ellas procediere, porque lo demás ha de haber S.M. por concierto y capitulación que hay con el dicho duque mi señor, las cuales vos arrendó» ${ }^{37}$.

Sea como fuere, la renta de salinas que ingresaban los Guzmanes oscilaba en Huelva entre 200.000 y 230.000 maravedíes en torno al año 1515 y en San Juan del Puerto entre 60.000 y 75.000 maravedíes (Ladero, 1992: 114). A esta cantidad de recursos había que sumarle la cuantía económica procedente de otras explotaciones distribuidas por la costa andaluza; en este sentido, la Casa de Medina Sidonia hacia el año 1650 obtenía en concepto de la sal 800.000 maravedíes, 3,5\% del total de sus ingresos (Salas, 2008: 56). Como práctica habitual la hacienda ducal acostumbraba a arrendar la producción de sal, tal como sucedió con las salinas alquiladas en 1564 a Agustín de Abreu -vecino y regidor de la villa de Huelva-, quien pagaba por el

35. AHN, Sección Nobleza, Osuna, C110, D. 1-11, fols. 18-22. AFCM, leg. 2429, sin foliar, años 1513 y 1521-1524.

36. Real cédula del 10 de agosto de 1564 (López, Ayarzagüena y Valiente, 2017: 60).

37. AHN, Sección Nobleza, Baena, C.253, D. 302-304. 
aprovechamiento de ellas medio ducado por cada cahíz durante nueve esquilmos $\mathrm{y}$ «en precio cada uno de 200 ducados de oro» ${ }^{38}$.

Décadas más tarde, las salinas de Huelva y San Juan del Puerto formaron parte del condado de Saltés y del mayorazgo fundado por Alonso Pérez de Guzmán-duque de Medina Sidonia- con el fin de que su hijo Rodrigo lo aportase como capital en las capitulaciones matrimoniales pactadas en 1611 para el casamiento con Brianda Zúñiga y Guzmán -hija de los marqueses de Ayamonte-; por tanto, continuaron vinculadas a los Guzmanes, aunque a partir de esa fecha estuvo bajo la jurisdicción de esta rama del linaje. Así se reflejaba en un expediente conservado en el fondo documental de la casa nobiliaria de Baena ${ }^{39}$ :

«... y por las cuales dicho Duque de Medina Sidonia se obligó a dar al referido Rodrigo, su hijo, la villa de Saltés, llamada antes de Aljaraque, con sus términos y jurisdicción y además diferentes bienes hasta componer 11.000 ducados de renta anual, todo ello por vía de mejora de quinto y tercio con cláusula de mayorazgo regular unido al de Ayamonte con otras condiciones (...) resultando con efecto del mencionado Duque D. Alonso y de su muger ejecutada en 1618 entre sus hijos y herederos se adjudicaron al referido D. Rodrigo, primer conde de Saltés, a la sazón ya difunto, y en su nombre y representación al hijo de este $\mathrm{D}$. Alonso diferentes bienes en pago de un haber vincular y entre ellos las salinas que están en término de la villa de Huelva con sus dos casas libres de tributo en 3.000 ducados y asimismo las salinas y casas de sal que están en la villa de San Juan del Puerto con la casa que está en la calle Toledillo en otros 3.000 reales libre de tributo...»

En el último cuarto del siglo XVIII las salinas de Huelva y de San Juan del Puerto continuaron perteneciendo a la jurisdicción señorial del condado de Saltés en la persona de Vicente Joaquín Osorio de Moscoso y Guzmán (Ruíz, 1999: 183. Salas, 2008: 472-473), si bien este linaje para entonces había unido su título al del marquesado de Astorga y al condado de Altamira. Con todo, aunque el control de la producción de la sal dependió directamente de las casas nobiliarias que ejercían la jurisdicción sobre sus respectivos territorios, no es menos cierto que a mediados del Setecientos debieron dejar un margen fiscal a la Real Hacienda ${ }^{40}$, como lo atestigua el hecho mencionado previamente de haber sido nombrada la villa de Huelva

38. AFCM, Leg. 736. Escritura de arrendamiento otorgada por Martín Dávila, en nombre del Duque de Medina Sidonia, en la villa de San Juan del Puerto, a 20 de junio de 1564, ante el escribano Juan de Robles.

39. AHN, Sección Nobleza, Baena, C. 253, D. 302.

40. El marqués de la Ensenada, con la intención de incrementar los ingresos fiscales, reorganizó las rentas de la sal otorgándole competencias directas a la Hacienda Real y estableció partidos provinciales; entre ellos se encontraba el de Huelva (López, Ayarzagüena y Valiente, 2017: 60-61). 
como cabeza de partido de la administración de la renta de salinas ${ }^{41}$, que integraba a localidades que habían formado parte de los señoríos de Moguer, Gibraleón, Huelva, Niebla y Ayamonte (Mora, 1762: 143).

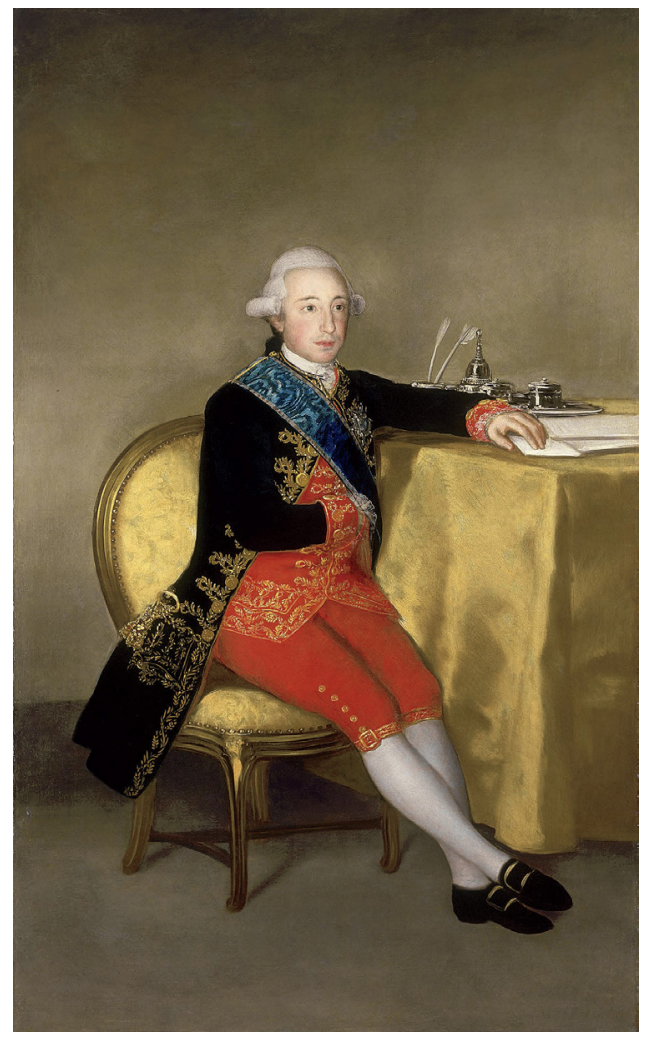

Imagen 3. Vicente Joaquín Osorio de Moscoso y Guzmán en 1787. Titular de las salinas de Huelva y de San Juan del Puerto, conde de Saltés, marqués de Astorga, y conde de Altamira, entre otros títulos nobiliarios. Fue uno de los primeros directores del Banco de San Carlos. Retrato realizado por Francisco de Goya (Colección del Banco de España)

Sin duda, las rentas generadas a las arcas señoriales por la elaboración de la sal propiciaron que sus titulares mostraran un incuestionable celo y se ocuparan de la vigilancia de las salinas con objeto de obtener la mayor cuantía posible de recursos económicos destinados a sus respectivas haciendas; de ahí que se preocuparan de

41. AGS, Catastro de Ensenada, Respuestas Generales, leg. 562, fol. 322. 
evitar potenciales perjuicios creando normativas tales como las ordenanzas aprobadas por el duque de Medina Sidonia en 1504, que pretendían impedir los robos efectuados por sus vasallos, así como los daños provocados por el ganado en las explotaciones salineras:

«Otrosí, porque en la ciudad, villas e lugares de mi tierra e señorío donde yo tengo salinas muchas personas se atreven a ir a ellas a sacar sal e la tomar e furtar sacada o por sacar e hacer panes de ella e haver otros provechos, mando que ninguno tome sal de las dichas salinas, sacada o por sacar, so pena de seiscientos maravedís (...) Otrosí, mando que ninguno salinero ni maestro de sacar sal que los arrendadores tuvieren puestos en las salinas saquen sal para sí ni para otra persona alguna sin licencia de los que tienen las dichas salinas so pena de seiscientos maravedís por cada vez que la dicha sal tomaren o dieren, ni menos fagan pan de la dicha sal (...) Otrosí, porque los bueyes e otros ganados huyen de los tábanos a donde hay salinas en los meses de abril y mayo e se suelen entrar en ellas e las ciegan e otras veces por comer la yerva, e de antigua costumbre está puesto un real de pena por cada buey...» (Galán, 2004: 168-169).

Por otra parte, la explotación de la sal en Moguer estuvo adscrita al señorío de los Portocarrero desde la Baja Edad Media. En este sentido, si en un principio dependió del monopolio regio, posteriormente Alfonso XI donó en 1328 las salinas de Garci Pérez a Alonso Jofre Tenorio -almirante mayor de Castilla (González Gómez, 1977: 125)-, de manera que sus descendientes como consecuencia de enlaces matrimoniales la mantuvieron integradas durante la Edad Moderna en el marquesado de Villanueva del Fresno al que perteneció el señorío de Moguer. Precisamente, Pedro Portocarrero, titular de la jurisdicción de ambos municipios y alcalde mayor de la ciudad de Sevilla, afirmaba en su testamento otorgado el 16 de mayo de 1518 que las salinas moguereñas formaban parte de su mayorazgo ${ }^{42}$.

Con todo, los beneficios que generaban la producción de la sal en el estuario del Tinto originaron conflictos entre señoríos; en concreto entre la jurisdicción de los Portocarrero en Moguer y servidores de la casa ducal de Medina Sidonia en el condado de Niebla. Ciertamente, la construcción de unas salinas en la dehesa de Mampoy por Diego de Oyón -corregidor de Niebla y criado del duque- dentro del término municipal de Moguer originó un largo contencioso impulsado por el señor de esta última localidad y por su concejo municipal, debido -según Pedro Portocarrero-a los perjuicios que le ocasionaba a otras salinas de su propiedad «muy antiguas que memoria de omnes non es en contrario» (Anasagasti y Rodríguez, 2006: 859). La citada dehesa se encontraba situada en el límite nororiental del término

42. Real Academia de la Historia (RAH), Signatura D-14, fol. 180v. Número de registro: 20547. 
de Moguer, limítrofe con el de Niebla, y formaba parte de los bienes de propios del cabildo secular moguereño. La primera constancia documental de la existencia de este conflicto se tiene mediante una orden real dada por los Reyes Católicos en Córdoba el 26 de noviembre de 1478 por la que se mandaba a Diego de Oyón la paralización de la construcción de las mencionadas salinas ${ }^{43}$; posteriormente, el 21 de octubre de 1484, a instancia del concejo de Moguer, los monarcas instaban al corregidor de Niebla a restituir los diversos perjuicios causados a los bienes y personas del municipio moguereño en la dehesa de Mampoy ${ }^{44}$. Por último, después de diferentes iniciativas judiciales del cabildo con el apoyo de los Portocarrero se produjo una sentencia regia definitiva en 1494 que obligaba a Diego de Oyón a devolver la dehesa ocupada (González Gómez, 1977: 88-89). Como consecuencia de ello tras la sentencia de la Real Audiencia y Chancillería de Ciudad Real el lugar en litigio fue ocupado por el señor de Moguer, el cabildo secular y sus vecinos; pero este hecho no significó, frente a lo que podía suponerse en un principio, la finalización de la contienda, pues lo cierto es que los Reyes Católicos debieron intervenir de nuevo el 3 de junio de 1500 ordenando la ejecución de la condena porque «mucha gente de a caballo e peones de Niebla con mano armada»-según ellos por orden del duque de Medina Sidonia- derribaron una parte de la casa que estaba construyendo un criado de Pedro Portocarrero con su autorización en la dehesa de Mampoy ${ }^{45}$.

Desde luego este contencioso analizado y la documentación generada lo que demuestra es que la gestión de la elaboración de la sal fue una actividad controlada por las casas señoriales en las marismas del Tinto de manera que la Corona se limitaba, principalmente, a ejercer como árbitro judicial cuando se originaban disputas o enfrentamientos con acciones de fuerza entre las diferentes jurisdicciones nobiliarias asentadas en esta zona.

Por otro lado, las salinas de Moguer, desde la Baja Edad Media, han sido la única expresión representativa en el estuario del río Tinto del modelo castellano de enajenación de la renta de la sal concedida a diversas instituciones religiosas por la Monarquía ${ }^{46}$, ya que Pedro I otorgó a las religiosas del convento de Santa Clara de esta localidad los derechos sobre las salinas que había en la zona de La Ribera (Ropero, 2003: 13). Su padre, Alfonso XI, el 25 de octubre de 1337, también había participado en este proceso de enajenación confirmando una orden real de Fernando IV, dictada el 24 de febrero de 1310, en la que mandaba a los recaudadores y arrendadores del

43. AGS, RGS, leg. 147811, fol. 32 .

44. AGS, RGS, leg. 148410, fol. 212.

45. Real provisión comisionando al licenciado Francisco de Molina para que ejecute de nuevo la sentencia condenatoria por la ocupación ilegal de la dehesa existente en el término municipal de Moguer (Anasagasti y Rodríguez, 2006: 1291-1292).

46. Esta tesis general de las enajenaciones castellanas es fruto de las investigaciones realizadas por el historiador medievalista Julio González González (Ladero, 1993: 91). 
almojarifazgo de Sevilla que entregasen al monasterio de San Clemente de esta ciudad 500 maravedíes anuales procedentes de la aduana hispalense y 10 cahices de sal de la alhóndiga ${ }^{47}$. Con todo, una vez que la explotación de la sal pasó a depender de la jurisdicción señorial, el almirante Alonso Jofre Tenorio -fundador del convento de Santa Clara- permitió que las monjas continuaran detentando prerrogativas sobre la producción y comercialización del cloruro de sodio; en efecto, tanto los Portocarrero como los Guzmanes confirmaron las prácticas anteriormente concedidas por sus ascendientes ante las reclamaciones realizadas por las religiosas, tal como se recogía en la carta dirigida por Martín Fernández Portocarrero a los alcaldes de la villa de Moguer el 16 de noviembre de 1393, en la que también se refrendaban los privilegios ratificados por Alfonso Ferrández -su padre-:

«Fágovos saber que la abadesa e duennas de mi monesterio de Santa Clara del dicho mi lugar de Moguer, se me querellaron diciendo quel Almirante e donna Elvira Álvarez, mis bisabuelos, que les ovieron fecho merçed e dado en limosna çiento e çinquenta cafizes de sal para su mantenimiento, con toda la renta e derecho que della pertenesçía, para que la pudiesen vender a esta dicha mi villa e en la Vicaría de Niebla, con tal condición que los almoxerifes que non pudiesen vender en los lugares sobredichos nin los vecinos e moradores dellos (...) E yo mandeles dar ende esta, por que vos mando que les guardedes e fagades guardar todas las cartas e previllegios e graçias e libertades e merçedes que los dichos bisabuelos les fizieron e las que Alfonso Ferrandez, mi padre, que dé Dios santo parayso, les dio en espeçial que les sea guardado la vendida de la dicha sal con el derecho della, segund que es contenido en el dicho previllegio: que los dichos almoxerifes non puedan vender nin vendan sal a la dicha Vicaria de Niebla nin aquí a la dicha mi villa, so pena de seysçientos maravedís para las dichas duennas, por cada vez e para cada persona que la vendiere...» (Vilaplana, 1975: 254-255)

Una orden de semejante contenido fue dictada por el conde Juan de Guzmán a los alcaldes de Niebla varios meses antes, el 7 de julio de 1393, con el fin de preservar el monopolio de venta de la sal que les había otorgado el almirante Jofre Tenorio a las clarisas $^{48}$. Documentalmente consta que el privilegio que disfrutaba esta comunidad franciscana femenina de disponer anualmente de una cifra superior a los cien cahices de sal estuvo vigente, al menos, durante el siglo XVI; no en vano, en 1565, Cristóbal Martín de Escacena -recaudador del marqués de Villanueva del Fresno y señor de Moguer- entregó al convento de Santa Clara 32.640 maravedíes correspondientes a

47. AMS, CS. Secc. Leg. 3, no 186 (traslado del escribano Gil García, 19 de septiembre de 1339). (García, 1988: 65).

48. Ibidem, pp. 252-254. 
240 cahices por dos años cumplidos ${ }^{49}$. Este dato y otros documentos existentes en los protocolos notariales de Moguer parecen indicar que la cuantía de los cahices obtenidos por la comunidad clarisa se redujo de los 150 anuales otorgados en el siglo XIV a los 120 que se registraron en las décadas de los sesenta y setenta del siglo XVI, ya que el convento vendió en los años 1576 y 1577 esa cantidad de cloruro de sodio por 1.000 reales de plata por anualidad a los vecinos de Moguer que tenían arrendadas las salinas de la villa ${ }^{50}$.

\section{EL COMERCIO DE LA SAL}

Desde comienzos de la Edad Moderna los puertos naturales del río Tinto fueron lugares de escala o de destino en las rutas marítimas que unían el océano Atlántico con el mar Mediterráneo, lo cual posibilitaba que los mercaderes de diferentes nacionalidades (flamencos, bretones, portugueses, ingleses, irlandeses e italianos) desarrollasen actividades comerciales en esta zona. En este marco, la sal era un producto cotizado y demandado por las embarcaciones extranjeras, tal como se atestigua en las ordenanzas de la villa de Palos otorgadas el dos de septiembre de 1485, en las que el duque de Medina Sidonia, el conde de Miranda y Pedro de Silva -señores de la villa- trataron de regular y controlar la venta de este producto esencial para las pesquerías:

«Primeramente, que por cuanto han seido informados que a los navíos estrangeros que solían venir a esta villa para servicio de ella y de las rentas de los señores, les hasian tomar la sal de los dichos señores a los prezios que son obligados los navíos de la villa, que por quanto fallavan ser agravio, mandan e quieren que los tales navíos estrangeros, salvo si fueren fletados prinzipalmente por algund vesino de la dicha villa, pueda tomar e llevar libre e desembargadamente sal, así como los otros fornimientos de donde quiera que ellos los quisieren llevar, e más su provecho los fuere, con tal condizión que si la mitad de la gente del navío o de ende arriba fuere de la dicha villa, sea obligado a venir a vender el pescado que así pescaren al puerto de esta villa, so la pena de cinco mil maravedíes» (Ladero, 1978: 482).

De igual modo es conocido que la sal andaluza era un producto transportado con frecuencia en los fletes de retorno en la ruta de comercio establecida entre

49. Archivo Histórico de Moguer, Fondo notarial, leg. 7, fol. 375v. Dato cedido generosamente por el investigador Federico Ortega Flores.

50. Entre los arrendadores de las salinas de Moguer en la década de los setenta del quinientos se encontraban Pedro Rodríguez de Ribera, Pedro García de Ana Márquez, Alonso Benítez Gallego, Diego Martín Blanco, y Miguel Martín de Godoy, todos ellos avecindados en Moguer. AHM, Fondo notarial, leg. 17, fols. 602r-605r, 607v y 612v. Agradezco al mencionado Federico Ortega estas referencias documentales amablemente ofrecidas. 
Italia y Flandes (Ladero, 1987: 831). Asimismo, la documentación conservada en el Archivo General de Indias en relación con el cobro del impuesto de avería nos informa sobre la actividad mercantil practicada por los navíos extranjeros especialmente en el puerto de San Juan, donde llegaban en el siglo XVI urcas, que por el valor de 300 ó 400 ducados cargaban este tipo de barco cuyo casco valía entre cuatro y cinco mil ducados. Aunque el documento redactado el 11 de julio de 1572 por el licenciado Tobar ${ }^{51}$, en representación de la villa de San Juan del Puerto, no reseña la nacionalidad de los propietarios de las mencionadas urcas ${ }^{52}$, es sabido que se trata de embarcaciones utilizadas con asiduidad por holandeses y flamencos con capacidad para navegar por costas bajas similares a la profundidad que tenía el estuario del Tinto (Dávila, 2015: 51). A este respecto, si consideramos las actividades comerciales desarrolladas por los extranjeros en otras localidades de la jurisdicción de los duques de Medina Sidonia puede observarse que en Sanlúcar de Barrameda hubo presencia de mercaderes franceses, ingleses, daneses, alemanes y, principalmente, flamencos, dedicados al negocio de la sal (Moreno, 2018: 151).

Sea cual fuere la afluencia de comerciantes de otras nacionalidades, la dedicación de San Juan del Puerto a la venta de sal no sorprende si se tiene en cuenta la existencia de salinas en su término municipal y el hecho de que desde principios de la Edad Moderna ocupó el primer puerto en valor fiscal en cuanto a operaciones de carga realizadas en el área marítima de la costa onubense -23.907 maravedíes- (González Cruz, 2012: 222-223; Palenzuela y Aznar, 2010: 66), seguido en segundo lugar por Huelva -11.022,50 maravedíes-. Esta posición de primacía de la villa en el embarque de productos continuó en los siglos XVII y XVIII a consecuencia de su situación geográfica como nudo de comunicaciones del condado de Niebla, enclave de paso desde los señoríos de Palos y Moguer, así como lugar de tránsito hacia la ciudad de Sevilla y su hinterland, reino de Portugal, el Andévalo, la Sierra de Huelva y Extremadura (Pulido, 1992: 99). Desde luego, este florecimiento mercantil de la localidad y la afluencia de comerciantes foráneos, capitanes y maestres motivó que Alonso Pérez de Guzmán -duque de Medina Sidonia- decidiera a fines del siglo XVI nombrar un cónsul de las «naciones extranjeras» en la villa de San Juan del Puerto con el fin de que los atendiera «haciendo sus cuentas y solicitando y defendiendo sus causas y negociaciones según de la manera que lo suelen y deben hacer los cónsules de las dichas naciones» ${ }^{53}$.

51. Archivo General de Indias (AGI), Justicia, leg. 1150, N. 1, R. 2.

52. La información proporcionada por diferentes listados que registran la presencia de urcas en las costas del Golfo de Cádiz y del río Guadalquivir en el siglo XVI indican que disponían de una capacidad de carga entre 475 y 300 toneles de arqueo medio (Casado, 1998: 180-181).

53. Comunicación del duque de Medina Sidonia al cabildo municipal de San Juan del Puerto sobre la designación de Andrés Ochoa, vecino de la villa, como cónsul de las naciones extranjeras en esta localidad. AMSJ, Actas capitulares, cabildo de 25 de enero de 1591, leg. 1, fol. 273. 


\section{Befthaybingbe vande alopagie om Dengelbelen} mertelt Cloot / ghedaen Doos Olivier van Noort ban V trecht, Gaterael ober biex Drbepen /te weten: bet Bebtp Mauritius als zomirael bat tweberom glyecomen ia: Hendrick Fredrick Bice-210.

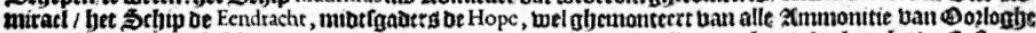
enoe victualie/op Jebbende 248. man/om te gatn ooo? de Strate Mageilanes, te bamocien langbs oc Cuften

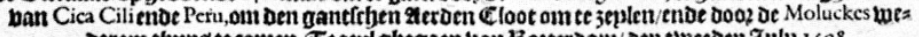

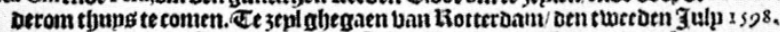

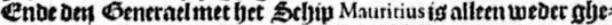
hect moe פgatnt van Zugutti/Anno 1601 .

Daer in dat vertelt vvort zyne vwonderlijcke avontueren, ende in verfecheyden Figueren afghebeelt, vele Vremdigheden dat hem is bejegent, tvvelck hy ghefien ende dat hem vvedervaren is.

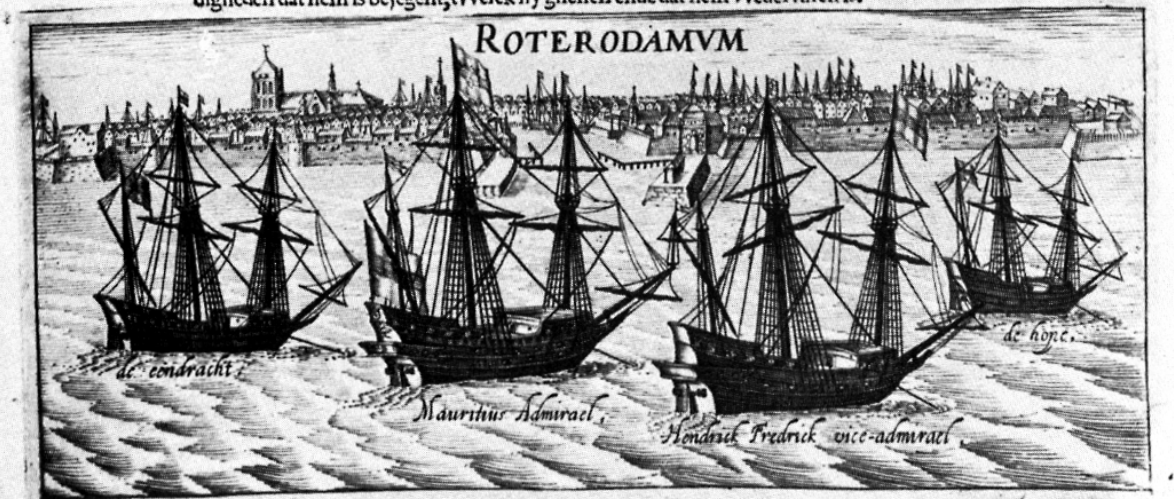

Men vintere coop tot Rotterdam, bv Ian van Waesberghen, op de Marct inde Pame. Endetor

Imagen 4. Grabado con urcas, embarcaciones de carga que transportaban la sal desde San Juan del Puerto a otros puertos europeos en el siglo XVI. Portada de libro (Noort, 1602)

Con todo, los puertos del río Tinto no fueron los únicos suministradores de sal a las embarcaciones con destino a los Países Bajos, pues durante el siglo XVII se advierte la presencia de un importante tráfico comercial de este producto ejercido por los holandeses en diferentes puertos andaluces con el fin de abastecerse de la materia prima necesaria para procesar y conservar el pescado, así como para la industria de quesos, cecina y mantequilla ${ }^{54}$. Además, el proceso de refinado que efectuaban les generaba sustanciosos beneficios, pues compraban la sal bruta a bajo precio en los territorios hispánicos y la vendían en otros países europeos multiplicando su valor varias veces (Varela, 1980: 53; Dávila, 2015: 48).

54. Real decreto redactado el 10 de agosto de 1679 ordenando que los navíos neerlandeses que transportaban sal se situaran en la bahía de Cádiz según lo tratado con los almirantazgos de Holanda. AHN, Estado, leg. 604, exp. 8. 
En fin, el análisis realizado ha permitido comprobar que la producción salinera en el estuario del Tinto fue un elemento fundamental en el desarrollo de las actividades pesqueras y comerciales desde la Baja Edad Media hasta fines de la Edad Moderna hasta el punto de que influyeron decisivamente en la proyección nacional e internacional de sus puertos, gracias también a las conexiones establecidas con las rutas mediterráneas, las aguas atlánticas de África y diferentes países europeos. Sin duda, el valor de este recurso económico motivó que las diferentes casas nobiliarias se interesaran por obtener la titularidad de las salinas y consiguieran de la Corona los privilegios necesarios para explotarlas, a pesar de que en su origen se trataba de una prerrogativa regia. En cualquier caso, la sal y los productos elaborados con ella contribuyeron a la preparación de las armadas que participaron en las empresas marítimas que han tenido a los marinos de las localidades situadas en las dos orillas del río Tinto como protagonistas de hitos trascendentales en la historia universal tales como el descubrimiento de América o las exploraciones efectuadas en el contexto de la expansión atlántico-africana.

\section{BIBLIOGRAFÍA}

Anasagasti Valderrama, A. Ma , y Rodríguez Liañez, L (2006). Niebla y su tierra en la Baja Edad Media. Historia y documentos, vol. II. Huelva: Diputación Provincial.

Armona y Murga, J.A. (2012). (Edición, introducción y notas de Álvarez Barrientos, J., Imízcoz, J.M. y Aranburuzabala, Y.) Noticias privadas de casa útiles para mis hijos. Asturias: Ed. Trea.

Muro Orejón, A. (ed.) (1964), Pleitos Colombinos, tomo VIII. Sevilla: Escuela de Estudios Hispanoamericanos.

Aznar Vallejo, E. (2002). La expedición de Charles de Valera a Guinea. Precisiones históricas y técnicas. En la España Medieval, 25, 403-423.

Casado Soto, J.L. (1998). Aproximación a la tipología naval cantábrica en la primera mitad del siglo XVI. Itsas Memoria. Revista de Estudios Marítimos del País Vasco, 2, 169-191.

Dávila, R. I. (2015). La sal: objetivo codiciado por Holanda en las provincias de Nueva Andalucía y Venezuela durante el siglo XVII. Tiempo y espacio, 64, 45-71.

Del Barco y Gasca, A. J. (1755). Dissertación histórico-geográphica sobre reducir la antigua Onuba a la villa de Huelva. Sevilla: Imp. Joseph Padrino.

Espinalt García, B. (1795). Atlante español o descripción general geográfica, cronológica e histórica de España, tomo XIV. Madrid: s.n.

Fernández Navarrete, M. (1829). Colección de los viajes y descubrimientos que hicieron por mar los españoles desde fines del siglo $X V$, con varios documentos inéditos concernientes a la bistoria de la marina castellana y de los establecimientos españoles en Indias, tomo III. Madrid: Imprenta Real.

Galán Parra, I. (2004). Las ordenanzas ducales del año 1504. Administración y economía en los señoríos de los duques de Medina Sidonia. Almonte (Huelva): Ayuntamiento. 
DAVID GONZÁLEZ CRUZ

LA RED DE SALINAS Y EL COMERCIO DE LA SAL EN EL ESTUARIO DEL TINTO DURANTE LA EDAD MODERNA: HUELVA, SAN JUAN DEL PUERTO, PALOS DE LA FRONTERA Y MOGUER

García Fernández, M. (1988). Regesto documental andaluz de Alfonso XI (1312-1350). Historia. Instituciones. Documentos, 15, 1-125.

González Cruz, D. (1995). La tierra y los hombres en la Huelva del Antiguo Régimen. Huelva: Diputación Provincial.

González Cruz, D. (2012). El puerto de San Juan en tiempos del descubrimiento de América y la expansión atlántica. En D. González Cruz (coord.), Descubridores de América. Colón, los marinos y los puertos. Madrid: Sílex, 201-243.

González Cruz, D. (2016). Contribuciones y estrategia fiscal de los Reyes Católicos en el entorno de los puertos del río Tinto durante el proceso de gestación y financiación del primer viaje colombino. Historia, 49, 111-132.

González Cruz, D. (2017). Localización histórico-geográfica de las tierras explotadas por la familia de Cristóbal Colón en el puerto de San Juan (Huelva, España). Anuario de Estudios Americanos, 74 (2), 415-438.

González Gómez, A. (1977). Moguer en la Baja Edad Media (1248-1538). Huelva: Diputación Provincial.

Iglesias Rodríguez, J.J. (2003). Monarquía y nobleza señorial en Andalucía: estudios sobre el señorio de El Puerto (siglos XIII-XVIII). Sevilla: Universidad de Sevilla.

Izquierdo Labrado, J. (1988). Palos de la Frontera en el Antiguo Régimen (1380-1830). Palos de la Frontera: Ayuntamiento.

Ladero Quesada, M.A. (1978). Palos en vísperas del Descubrimiento. Revista de Indias, 153-154, 471-506.

Ladero Quesada, M.A. (1987) La renta de la sal en la corona de Castilla (siglos XII-XVI). En Homenaje al profesor Juan Torres Fontes. Murcia: Universidad de Murcia y Academia Alfonso X el sabio, 821-837.

Ladero Quesada, M.A. (1992). Niebla, de reino a condado. Noticias sobre el Algarbe andaluz en la Baja Edad Media. Huelva: Diputación Provincial.

Ladero Quesada, M.A. (1993). Fiscalidad y poder real en Castilla (1252-1369). Madrid: Editorial Complutense.

Ladero Quesada, M.A. (2015). Guzmán. La casa ducal de Medina Sidonia en Sevilla y su reino (1282-1521). Madrid: Dykinson.

López Cidad, F., Ayarzagüena Sanz, M. y Valiente Cánovas, S. (2017). La sal de España durante el Medievo y la Edad Moderna, De Re Metallica, 28, 47-62.

Malpica Cuello, A. y González Alcantud, J.A. (2003). La sal: del gusto alimentario al arrendamiento de salinas. Granada: Diputación Provincial.

Martín Gutiérrez, E. (2010). Los salineros durante los siglos XV y XVI. Una propuesta desde la bahía de Cádiz, Societá e Storia, 129, 419-451.

Mena García, Mª C. (1988). Sevilla y las flotas de Indias. La Gran Armada de Castilla del Oro (1513-1514). Sevilla: Universidad de Sevilla.

Mora Negro y Garrocho, J. A. (1762). Huelva ilustrada. Breve historia de la antigua y noble villa de Huelva. Sevilla: Imprenta de Jerónimo Castilla. 
Moreno Ollero, A. (2018). Sal para las almadrabas del duque de Medina Sidonia (El abastecimiento de las pesquerías de atún de Conil y Zahara en la primera mitad del siglo XVI). Cartare. Boletín del Centro de Estudios de la Costa Noroeste de Cádiz, 8, 144-154.

Palenzuela Domínguez, N. y Aznar Vallejo, E. (2010). El comercio de los puertos del Condado en 1502. El testimonio del almojarifazgo. Huelva en su historia, 13, 63-134.

Pardo Rodríguez, Ma . L. (1980). Huelva y Gibraleón (1282-1495). Documentos para su historia, Huelva: Instituto de Estudios Onubenses «Padre Marchena».

Pérez de Tudela, J. (dir.) (1994). Colección documental del descubrimiento (1470-1506), tomo II, Madrid: Editorial MAPFRE.

Pulido Bueno, I. (1992). Expansión de un núcleo portuario-mercantil onubense. Los dos primeros siglos de la villa de San Juan del Puerto. En D. González Cruz (dir.), Cinco siglos de historia de la villa de San Juan del Puerto (1468-1992). De la tradición marítima al proceso de industrialización. San Juan del Puerto (Huelva): Ayuntamiento.

Ropero Regidor, D. (2003). Moguer y América en la era de los descubrimientos. Moguer: Fundación Municipal de Cultura.

Ruíz González, J.E. (1999). Los pueblos de Huelva en el siglo XVIII (Según el diccionario del geógrafo real D. Tomás López). Huelva: Diputación Provincial.

Salas Almela, L. (2008). Medina Sidonia: el poder de la aristocracia, 1580-1670. Madrid: Centro de Estudios Andaluces-Marcial Pons.

Van Noort, O. (1602). Beschryvinghe van de voyagie om den gebeelen werelt-cloot, ghedaen door (...), van Utrecht, generael over vier schepen... om te zeylen door de Strate Magellanes, te handelen langs de custen van Cica, Chili ende Peru, om den gantschen aerden cloot ende door de Molucques wederon thuys te comen...

Varela Marcos, J. (1980). Las salinas de Araya y el origen de la Armada de Barlovento. Caracas: Academia Nacional de la Historia.

Vilaplana, Ma.A. (1975). La colección diplomática de Santa Clara de Moguer, 1280-1483. Sevilla: Universidad de Sevilla. 